\title{
What is kangaroo mother care? Systematic review of the literature
}

Grace J Chan ${ }^{1,2,3}$, Bina Valsangkar ${ }^{3}$, Sandhya Kajeepeta ${ }^{2}$, Ellen O Boundy ${ }^{2}$, Stephen Wall ${ }^{3}$

\footnotetext{
${ }^{1}$ Department of Pediatrics, Harvard Medical School, Boston, MA, USA

${ }^{2}$ Department of Global Health and Population, Harvard T.H. Chan School of Public Health, Boston, MA, USA

${ }^{3}$ Saving Newborn Lives, Save the Children, Washington, DC, USA
}

Background Kangaroo mother care (KMC), often defined as skinto-skin contact between a mother and her newborn, frequent or exclusive breastfeeding, and early discharge from the hospital has been effective in reducing the risk of mortality among preterm and low birth weight infants. Research studies and program implementation of KMC have used various definitions.

Objectives To describe the current definitions of KMC in various settings, analyze the presence or absence of KMC components in each definition, and present a core definition of KMC based on common components that are present in KMC literature.

Methods We conducted a systematic review and searched PubMed, Embase, Scopus, Web of Science, and the World Health Organization Regional Databases for studies with key words "kangaroo mother care", "kangaroo care" or "skin to skin care" from 1 January 1960 to 24 April 2014. Two independent reviewers screened articles and abstracted data.

Findings We screened 1035 articles and reports; 299 contained data on KMC and neonatal outcomes or qualitative information on KMC implementation. Eighty-eight of the studies (29\%) did not define KMC. Two hundred and eleven studies (71\%) included skin-to-skin contact (SSC) in their KMC definition, 49 (16\%) included exclusive or nearly exclusive breastfeeding, 22 (7\%) included early discharge criteria, and 36 (12\%) included follow-up after discharge. One hundred and sixty-seven studies (56\%) described the hours per day of SSC.

Conclusions There exists significant heterogeneity in the definition of KMC. A large number of studies did not report definitions of KMC. Skin-to-skin contact is the core component of KMC, whereas components such as breastfeeding, early discharge, and follow-up care are context specific. To implement KMC effectively development of a global standardized definition of KMC is needed.

\section{Correspondence to:}

Grace J Chan

677 Huntington Ave

Building 1, \#1108

Boston, MA

USA 02115

grace.chan@hsph.harvard.edu
Globally, 44\% of under-five deaths occur during the neonatal period, and the proportion of under-five deaths due to neonatal causes continues to rise $[1,2]$. Preterm birth (before 37 weeks gestation) accounts for 35\% of neonatal deaths. Low birth weight (defined as $<2500 \mathrm{~g}$ ) is commonly used as a surrogate measure of preterm birth [3]. Preterm and low birth weight infants who survive the neonatal period are more likely to experience neonatal morbidities including acute respiratory, gastrointestinal, immunologic, central nervous system, hearing and vision problems than both term and normal weight infants [4]. 
A significant proportion of deaths among preterm and low birth weight infants is preventable. There is evidence that kangaroo mother care (KMC), when compared to conventional neonatal care in resource-limited settings, significantly reduces the risk of mortality in infants born in facilities who are clinically stable and weighing less than $2000 \mathrm{~g}$ [5]. KMC also reduces the risk of hypothermia, severe illness, nosocomial infection, and length of hospital stay, and improves growth, breastfeeding, and maternalinfant attachment $[5,6]$.

Despite strong evidence for mortality and morbidity reduction in low-and middle-income settings and endorsement from the World Health Organization (WHO), country-level adoption and implementation of KMC has been limited. In a systematic assessment of health system bottlenecks among countries with a high burden of neonatal deaths, KMC was identified as an intervention with significant health systems barriers to scale-up including leadership and governance, health financing, health workforce, health service delivery, health information systems, and community ownership and partnership [7]. Health intervention priority-setting tools, such as the Lives Saved Tool and Child Health and Nutrition Research Initiative methodology, have identified KMC as a high priority intervention based on criteria such as mortality benefit and equity [8,9].

In response to limited global uptake of KMC, in 2013, a group of newborn health stakeholders led by the Bill and Melinda Gates Foundation and Save the Children's Saving Newborn Lives Program launched a global KMC Acceleration Convening. The goal was to address barriers to implementation, increase uptake of KMC as part of an integrated Reproductive Maternal Newborn and Child Health package, and identify research priorities [10]. In addition to implementation barriers, a lack of a clear definition of KMC has made effective coverage at scale of KMC challenging. A multi-country study in Africa found variation in KMC implementation across facilities in countries with national commitment to KMC [11]. Regional, country, and facility differences in health worker capacity, financial resources, leadership, health information systems, and cultural and community structures create challenges to developing and adopting a global definition of KMC.

The WHO has defined KMC as early, continuous, and prolonged skin-to-skin contact (SSC) between the mother and preterm babies; exclusive breastfeeding or breast milk feeding; early discharge after hospital-initiated KMC with continuation at home; and adequate support and followup for mothers at home [12]. While the WHO provides guidance on the components of KMC, guidance on the operationalization and clinical implementation of KMC are needed. There are significant variations in the timing of initiation, duration of SSC, positioning, necessary equipment and supplies, discharge criteria, follow-up frequency, indicators and measurement, and health workforce needs. The variations in these components have differential effects on preterm and low birth weight outcomes. As the global newborn health community begins to accelerate implementation of KMC, a standardized operational definition is needed. We conducted a systematic review of the KMC literature to 1) describe the current definitions of $\mathrm{KMC}$ in various settings, 2) analyze the presence or absence of WHO KMC components in each definition, and 3) present a core definition of KMC-common components that are present in at least $70 \%$ of all studies and programs-and describe how KMC definitions vary by context. This review provides a basis for development of an operational definition and clinical standards to accelerate the uptake of KMC globally.

\section{METHODS}

We searched PubMed, Embase, Web of Science, Scopus, and WHO regional databases: AIM, LILACS, IMEMR, IMSEAR, and WPRIM using the search terms "kangaroo mother care", "kangaroo care", and "skin to skin care" with no language restrictions from 1 January 1960 to 24 April 2014 for original reports including case-control studies, cohort studies, randomized control trials, and case series with 10 or more participants (see Online Supplementary Document for the review protocol and full search strategy). Following PRISMA guidelines, studies were included if they contained at least one of the following: the amount of time KMC was practiced, an association between KMC (as an isolated exposure, not part of a larger package) add any outcome, barriers to implementing KMC or factors necessary for successful implementation of KMC. Exclusion criteria were non-human subjects, case series or descriptive studies with fewer than 10 participants, and non-primary data collection or analysis (eg, reviews, meeting abstracts, editorials). Our population of interest included mothers, newborns, or mother-newborn dyads (not restricted to any specific ages) who have practiced KMC as well as health care providers, health facilities, communities, and health systems that have implemented KMC.

We also conducted hand-searches through the reference lists of the articles included in our review and published systematic reviews. Cochrane reviews were searched for relevant articles. To search the "grey literature" for unpublished studies, we explored programmatic reports and requested data from programs implementing KMC to obtain programmatic perspectives in addition to those provided by research studies. Reports were included following the same criteria as above.

Two independent reviewers examined titles, abstracts and full-text articles for inclusion into the review using a 
screening form based on our inclusion criteria. Using standardized data abstraction forms, two reviewers abstracted data independently from all included articles and reports. At each stage, reviewers compared results to ensure agreement. In the case of disagreement between the two reviewers, a third party acted as a tiebreaker. Native speakers abstracted data from articles in foreign languages. Languages for which a native speaker was not identified (ie, German, Finnish, Korean, Thai and Polish) were translated using an online translation software to assist with data abstraction. If an article or report were missing any information, we contacted the authors to request the data.

Using standardized forms, data were abstracted on study characteristics such as study design, country, sample size, location, and duration of follow-up. We abstracted data on KMC definitions including data on SSC, exclusive breastfeeding, early discharge from the facility, and follow-up and as well as other components [12]. We generated categorical variables for each component and calculated descriptive frequencies, means, medians and ranges for quantitative data.

\section{RESULTS}

\section{Study selection and characteristics}

Our search strategy yielded 1035 records of which 299 were included in our review (Figure 1). Details of each included study are found in Table S1 in Online Supplementary Document. Summary characteristics of the included studies are presented in Table 1. In the last five years, as KMC research gaps have gained growing attention, the number of studies conducted has increased. One hundred and thirty-four studies (45\%) were published in the last five years between 2010 and 2014, 134 (45\%) between 2000 and 2009, and 31 (10\%) between 1988 and 1999. Common study types were randomized control trials ( $n=85,28 \%)$, surveys or interviews ( $\mathrm{n}=58,19 \%)$, and cohorts $(n=43,14 \%)$. Other study types included pre-post studies, facility-level evaluations, non-randomized intervention studies, and randomized crossover trials. One hundred and forty-four studies (48\%) had less than 50 participants and 47 (16\%) had 200 or more participants. Geographically, 115 (38\%) of the studies took place in the Americas, 64 (21\%) in Europe, 44 (15\%) in Africa, 29 (10\%) in Southeast Asia, 20 (7\%) in Western Pacific, and $16(5 \%)$ in Eastern Mediterranean regions. More studies were in countries with low neonatal mortality rates (NMRs), ie, less than 5 per 100 live births $(n=130,43 \%)$, than in countries with high NMRs, ie, 30 or higher $(n=10,3 \%)$ [13]. The majority of studies, 192 (64\%), were in an urban setting. One hundred and seventy-five studies (59\%) took place in health facilities, 107 (36\%) in neonatal intensive

Table 1. Characteristics of included studies

\begin{tabular}{|c|c|c|}
\hline & $\mathrm{N}=299$ & $\%$ \\
\hline \multicolumn{3}{|l|}{ Year: } \\
\hline 2010 to 2014 & 134 & 44.82 \\
\hline 2000 to 2009 & 134 & 44.82 \\
\hline 1988 to 1999 & 31 & 10.36 \\
\hline \multicolumn{3}{|l|}{ Sample size: } \\
\hline$<50$ & 144 & 48.16 \\
\hline 50 to $<100$ & 61 & 20.40 \\
\hline 100 to $<200$ & 47 & 15.72 \\
\hline$\geq 200$ & 47 & 15.72 \\
\hline \multicolumn{3}{|l|}{ Study type: } \\
\hline Randomized control trial & 85 & 28.43 \\
\hline Surveys or interview & 58 & 19.40 \\
\hline Cohort study & 43 & 14.38 \\
\hline Pre-post intervention study & 33 & 11.04 \\
\hline Facilities evaluation & 23 & 7.69 \\
\hline Intervention trial & 15 & 5.02 \\
\hline Randomized cross over & 14 & 4.68 \\
\hline Other (chart review, case-control, cross over, surveillance) & 28 & 9.36 \\
\hline \multicolumn{3}{|l|}{ World Health Organization region: } \\
\hline Americas & 115 & 38.46 \\
\hline Europe & 64 & 21.40 \\
\hline Africa & 44 & 14.72 \\
\hline Southeast Asia & 29 & 9.70 \\
\hline Western Pacific & 20 & 6.69 \\
\hline Eastern Mediterranean & 16 & 5.35 \\
\hline Multiple regions & 4 & 1.34 \\
\hline Missing & 7 & 2.34 \\
\hline \multicolumn{3}{|l|}{ Neonatal mortality rate (death per 1000 live birth): } \\
\hline$<5$ & 130 & 43.48 \\
\hline 5 to $<15$ & 84 & 28.09 \\
\hline 15 to $<30$ & 66 & 22.07 \\
\hline$\geq 30$ & 10 & 3.34 \\
\hline Missing & 9 & 3.01 \\
\hline \multicolumn{3}{|l|}{ Setting (rural or urban): } \\
\hline Urban & 192 & 64.21 \\
\hline Urban and rural & 23 & 7.69 \\
\hline Rural & 10 & 3.34 \\
\hline Missing & 74 & 24.75 \\
\hline \multicolumn{3}{|l|}{ Population source: } \\
\hline Health facility & 175 & 58.53 \\
\hline Neonatal intensive care unit or stepdown unit & 107 & 35.79 \\
\hline Community or population-based surveillance & 11 & 3.68 \\
\hline Missing & 6 & 2.01 \\
\hline \multicolumn{3}{|l|}{ Gestational age: } \\
\hline Preterm 34 to $<37$ weeks & 57 & 19.06 \\
\hline Very preterm $<34$ weeks & 51 & 17.06 \\
\hline Full term $\geq 37$ weeks & 33 & 11.04 \\
\hline Mixed preterm and very preterm $<37$ weeks & 26 & 8.70 \\
\hline All gestational ages & 28 & 9.36 \\
\hline Missing & 104 & 34.78 \\
\hline \multicolumn{3}{|l|}{ Birth weight: } \\
\hline Low birth weight 1500 to $<2500 \mathrm{~g}$ & 52 & 17.39 \\
\hline Mixed low $<2500 \mathrm{~g}$ and very low birth weight $<1500 \mathrm{~g}$ & 45 & 15.05 \\
\hline All birth weights & 25 & 8.36 \\
\hline Very low birth weight $<1500 \mathrm{~g}$ & 21 & 7.02 \\
\hline Non low birth weight $\geq 2500 \mathrm{~g}$ & 9 & 3.01 \\
\hline Low birth weight vs non-low birth weight & 1 & 0.33 \\
\hline Missing & 146 & 48.83 \\
\hline
\end{tabular}




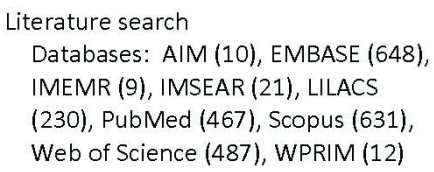

Records identified through database

searching $(n=2515)$

\begin{tabular}{|l|}
\hline Records identified \\
through crosscheck of \\
previous reviews $(n=18)$
\end{tabular}

Records identified through personal communication $(n=1)$

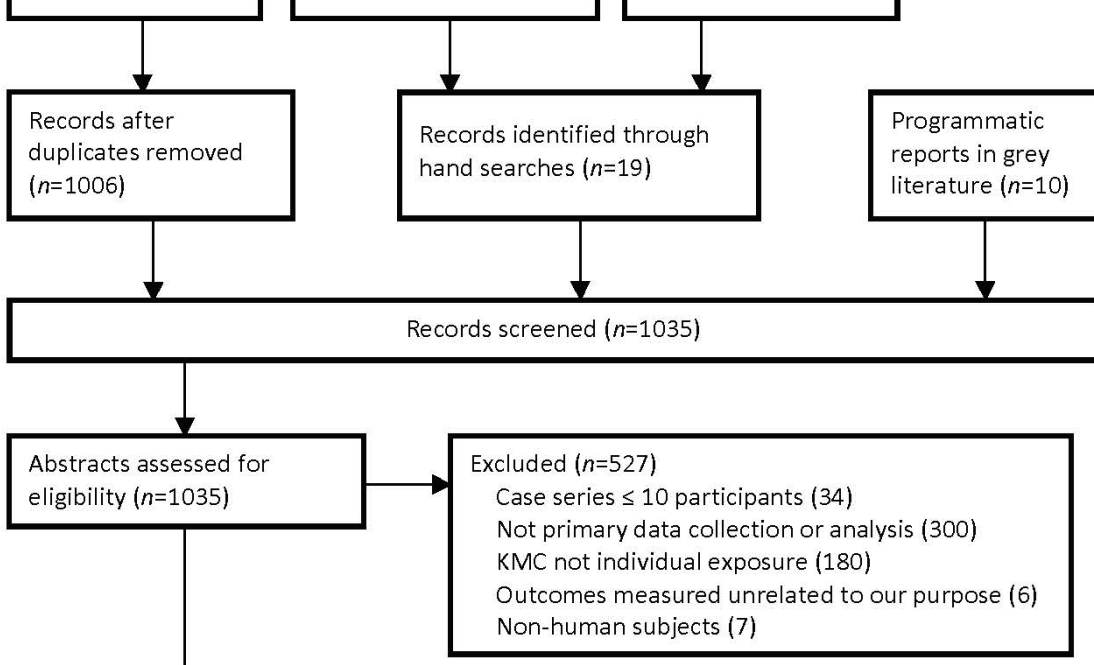

Excluded $(n=209)$

Case series $\leq 10$ participants ( 6 )

Full-text article not found (68)

Not primary data collection or analysis (83)

KMC not individual exposure (44)

Outcomes measured unrelated to our purpose (7)

Duplicate publication of data (1)

Figure 1. Flow diagram of study selection.

care units or stepdown units, and 11 (4\%) were community or population-based.

Most studies included preterm newborns less than 37 weeks gestation ( $\mathrm{n}=134,45 \%), 33$ studies (11\%) included only full term infants 37 weeks gestation or greater, 28 studies (9\%) included newborns of all gestational ages, and 104 studies (35\%) did not report gestational ages of the study participants. Similarly, 73 studies (24\%) were among low birth weight infants less than $2500 \mathrm{~g}$; 52 studies (17\%) included infants less than $2500 \mathrm{~g}$ to $1500 \mathrm{~g}$, and 21 (7\%) studies were among very low birth weight infants less than 1500 g. Forty-five studies (15\%) included a mix of low and very low birth weight newborns. Nine studies (3\%) were among newborns weighing $2500 \mathrm{~g}$ or greater and 25 studies (8\%) included newborns of all birth weights. One hundred forty-six studies (49\%) did not describe birth weight characteristics. Forty three studies (14\%) reported neither gestational age nor birth weight.

\section{KMC components}

The individual components of KMC varied across studies (Table 2). Kangaroo mother care was not defined in 88 studies (29\%). All 211 studies (71\%) with KMC definitions included SSC as a component. One-hundred fortyeight studies (50\%) included SSC only. For the additional components, 49 studies (16\%) included SSC and exclusive or near-exclusive breastfeeding, 36 (12\%) included SSC and follow-up after discharge from the health facility, and 22 (7\%) included early discharge from the health facility. 
Table 2. Description of kangaroo mother care components in studies

\begin{tabular}{lrr} 
KANGAROO MOTHER CARE COMPONENIS & $\mathbb{N}=\mathbf{2 9 9}$ & $\%$ \\
\hline Skin-to-skin contact only & 148 & 49.50 \\
\hline Skin-to-skin contact, breastfeeding & 25 & 8.36 \\
\hline Skin-to-skin contact, breastfeeding, follow-up & 16 & 5.35 \\
\hline Skin-to-skin contact, early discharge, follow-up & 13 & 4.35 \\
\hline $\begin{array}{l}\text { Skin-to-skin contact, breastfeeding, early discharge, } \\
\text { follow up }\end{array}$ & 7 & 2.34 \\
\hline Skin-to-skin contact, breastfeeding, early discharge & 1 & 0.33 \\
\hline Skin-to-skin contact, early discharge & 1 & 0.33 \\
\hline Undefined kangaroo mother care & 88 & 29.43 \\
\hline
\end{tabular}

\section{Skin-to-skin contact}

Among the studies that defined SSC as part of the KMC package, criteria for SSC initiation, SSC ending, and SSC duration were not well described (Table 3 and Table 4). In 43 studies (14\%), SSC was initiated after non-stability criteria were met, 27 studies (9\%) promoted immediate initiation of SSC within 60 minutes of birth, 76 studies (25\%) encouraged SSC after stability criteria were met, 18 studies (6\%) encouraged SSC after a painful procedure, and 135 (45\%) did not describe SSC initiation criteria. Forty-three studies observed initiation of SSC of which 4 (9\%) observed immediate initiation of SSC. Criteria for stability were nonspecific including the terms "clinically stable," "adapted to extra-uterine life," "can tolerate handling," and "without serious illness". More defined criteria included "satisfactory APGAR score," "stable weight," and "stable respiratory and hemodynamic parameters." Criteria to end SSC were largely non-specific with terms "one day or less," "until baby no longer accepts," or "until parent no longer accepts." More specific terms included "until reaches satisfactory weight [2000 grams or 2500 grams]". We compared descriptions of SSC with observations of SSC to differentiate promotion vs practice. Most studies ( $>85 \%$ ) did not include data on observations of SSC practiced (Table 3).

Data on the duration of SSC are needed to understand the benefits of SSC as well as the feasibility to scale KMC; however this was missing from most studies (Table 4). One hundred thirty-two studies (44\%) did not describe the number of hours per day SSC was promoted. Seventyeight studies (26\%) encouraged SSC for less than two hours per day, 15 of these studies examined the effect of SSC on painful procedures. Otherwise, the most common duration of SSC promoted was 22 hours or more ( $n=46$, $15 \%)$. Only 37 studies (12\%) observed duration of SSC practiced, of which six (2\%) observed at least 22 hours per day SSC practiced. SSC duration was also categorized inconsistently as continuous, intermittent, number of hours per session, number of sessions per day, and number of days. Definitions of the term continuous included 24 hours
Table 3. Promoted skin-to-skin contact characteristics compared to observed skin-to-skin contact characteristics

\begin{tabular}{|c|c|c|c|c|}
\hline & \multicolumn{2}{|c|}{$\begin{array}{l}\text { Promoted } \\
\text { SKIIN-TO-SKIN } \\
\text { CONTACT }\end{array}$} & \multicolumn{2}{|c|}{$\begin{array}{l}\text { OBSERVED } \\
\text { SKII-TO-SKIN } \\
\text { CONTACt }\end{array}$} \\
\hline & $\mathrm{N}$ & $\%$ & $\mathrm{~N}$ & $\%$ \\
\hline \multicolumn{5}{|l|}{ Skin-to-skin contact initiation: } \\
\hline After stability criteria were met & 76 & 25.42 & 11 & 3.68 \\
\hline After non-stability criteria were met & 43 & 14.38 & 28 & 9.36 \\
\hline Immediately, regardless of stability & 27 & 9.03 & 4 & 1.34 \\
\hline Prior to painful procedure & 18 & 6.02 & 0 & 0.00 \\
\hline Undefined or not applicable & 135 & 45.15 & 256 & 85.62 \\
\hline \multicolumn{5}{|l|}{ Skin-to-skin contact stability criteria: } \\
\hline Respiratory and/or hemodynamically stable & 28 & 9.36 & 2 & 0.67 \\
\hline Clinically stable-not specified further & 20 & 6.69 & 5 & 1.67 \\
\hline Adapted to extra-uterine life & 8 & 2.68 & 0 & 0.00 \\
\hline Without serious illness & 7 & 2.34 & 2 & 0.67 \\
\hline Can tolerate handling & 6 & 2.01 & 1 & 0.33 \\
\hline Stable weight & 4 & 1.34 & 1 & 0.33 \\
\hline Satisfactory APGAR score & 2 & 0.67 & 0 & 0.00 \\
\hline Term & 1 & 0.33 & 0 & 0.00 \\
\hline Undefined or not applicable & 223 & 74.58 & 288 & 96.32 \\
\hline \multicolumn{5}{|c|}{ When was skin-to-skin contact instructed to end? } \\
\hline One day or less & 48 & 16.05 & 5 & 1.67 \\
\hline Until baby no longer accepts & 22 & 7.36 & 1 & 0.33 \\
\hline Shortly after painful procedure & 13 & 4.35 & 0 & 0.00 \\
\hline After one day and up to two weeks & 11 & 3.68 & 5 & 1.67 \\
\hline $\begin{array}{l}\text { Until reaches satisfactory weight } \\
(2000 ; 3000 \mathrm{~g})\end{array}$ & 10 & 3.34 & 5 & 1.67 \\
\hline After two weeks & 8 & 2.68 & 5 & 1.67 \\
\hline Until parent or baby no longer accepts & 7 & 2.34 & 0 & 0.00 \\
\hline Until discharge & 4 & 1.34 & 3.00 & 1.00 \\
\hline Until parent no longer accepts & 4 & 1.34 & 0 & 0.00 \\
\hline Until reached satisfactory health status & 3 & 1.00 & 0 & 0.00 \\
\hline Undefined or not applicable & 169 & 56.52 & 275 & 91.97 \\
\hline
\end{tabular}

per day, continuous within sessions, or one continuous session but less than 24 hours a day.

\section{Breastfeeding}

Breastfeeding habits were reported in 105 (35\%) studies: 38 (13\%) reported exclusive breastfeeding, 22 (7\%) nearly-exclusive breastfeeding, and 35 (12\%) breastfeeding and supplemental feeding (Table 5). In most studies, breastfeeding initiation time was not reported $(n=261,87 \%)$. Breastfeeding was started immediately or within one hour of birth in 15 studies (5\%), between one and 24 hours after birth in two studies (1\%), and 24 hours or longer after birth in five studies (2\%). In nine studies (3\%) breastfeeding was started at KMC initiation, and seven studies (2\%) included physical maturity criteria for initiation of breastfeeding. Seventeen studies (6\%) described breastfeeding frequency in their patient population, 13 (4\%) studies reported women breastfeeding every two to three hours and four studies (1\%) reported women breastfeeding whenever possible. 
Table 4. Promoted skin-to-skin contact duration compared to observed skin-to-skin contact duration

\begin{tabular}{|c|c|}
\hline $\begin{array}{l}\text { PrOMOTED SKIN- } \\
\text { TO-SKIN CONTACT } \\
\text { DURATION }\end{array}$ & $\begin{array}{l}\text { OBSERVED SKIN- } \\
\text { TO-SKIN CONTACT } \\
\text { DURATION }\end{array}$ \\
\hline$N=299$ & $\mathrm{~N}=299$ \\
\hline
\end{tabular}

Skin-to-skin contact continuous or intermittent within session:

\begin{tabular}{llllll}
\hline Continuous within one session & & 117 & 39.13 & 16 & 5.35
\end{tabular}

\begin{tabular}{lllll}
\hline Continuous (24 h per day) & 44 & 14.72 & 7 & 2.34 \\
\hline
\end{tabular}

\begin{tabular}{lllll}
\hline Intermittent (multiple sessions) & 26 & 8.70 & 17 & 5.69 \\
\hline
\end{tabular}

\begin{tabular}{lllll}
\hline Undefined or not applicable & 112 & 37.46 & 259 & 86.62 \\
\hline
\end{tabular}

Skin-to-skin contact duration (hours per session):

\begin{tabular}{lrrrr}
\hline 1 to 2 sessions & 90 & 30.10 & 13 & 4.35 \\
\hline 3 to 4 sessions & 11 & 3.68 & 0 & 0.00 \\
\hline 5 to 8 sessions & 2 & 0.67 & 0 & 0.00 \\
\hline$\geq 8$ sessions & 0 & 0.00 & 1 & 0.33 \\
\hline Undefined or not applicable & 196 & 65.55 & 285 & 95.32 \\
\hline
\end{tabular}

Skin-to-skin contact duration (number hours per day):

\begin{tabular}{lrrrr}
\hline$<2 \mathrm{~h}$ & 78 & 26.09 & 13 & 4.35 \\
\hline 2 to $<4 \mathrm{~h}$ & 28 & 9.36 & 3 & 1.00 \\
\hline 4 to $<9 \mathrm{~h}$ & 13 & 4.35 & 8 & 2.68 \\
\hline 9 to $<12 \mathrm{~h}$ & 1 & 0.33 & 3 & 1.00 \\
\hline 12 to $<22 \mathrm{~h}$ & 1 & 0.33 & 4 & 1.34 \\
\hline$\geq 22 \mathrm{~h}$ & 46 & 15.38 & 6 & 2.01 \\
\hline Undefined or not applicable & 132 & 44.15 & 262 & 87.63
\end{tabular}

Skin-to-skin contact duration (number days):

\begin{tabular}{lrrrr}
\hline 1 to $5 \mathrm{~d}$ & 74 & 24.75 & 11 & 3.68 \\
\hline 6 to $<30 \mathrm{~d}$ & 19 & 6.35 & 8 & 2.68 \\
\hline$\geq 30 \mathrm{~d}$ & 5 & 1.67 & 1 & 0.33 \\
\hline Dependent on hospital stay & 7 & 2.34 & 1 & 0.33 \\
\hline Undefined or not applicable & 194 & 64.88 & 278 & 92.98
\end{tabular}

\section{Discharge criteria from facility}

Fourteen percent of studies ( $n=42)$ described the criteria used for hospital discharge in their study populations (Table 6). The most common criteria were clinical stability $(\mathrm{n}=19,6 \%)$ or meeting a specified weight gain or weight minimum cutoff ( $\mathrm{n}=15,5 \%)$. Seven studies ( $2 \%$ ) required a combination of adequate weight gain and exclusive breastfeeding prior to discharge. Most studies did not report when infants were discharged $(n=285,95 \%)$. Six studies (2\%) reported discharge within seven days of life and eight studies (3\%) reported discharge after seven days of life.

\section{Follow-up}

Sixty-one studies (20\%) described follow-up of infants after discharge, of which 29 studies (48\%) followed-up with newborns in health facilities, 22 studies (36\%) in homes, and 9 studies (15\%) in both facilities and homes (Table 6). Follow-up time varied from one month or less $(\mathrm{n}=8,3 \%)$ to six to 18 months ( $n=13,4 \%)$. Most studies $(n=270$, 90\%) did not report compliance with follow-up, 11 (4\%) reported $90 \%$ or higher compliance.
Table 5. Description of breastfeeding characteristics

\begin{tabular}{lrr} 
& N $=299$ & $\%$ \\
\hline Breastfeeding habits: & 38 & 12.71 \\
\hline Exclusive & 35 & 11.71 \\
\hline Mixed with other food & 22 & 7.36 \\
\hline Nearly exclusive & 8 & 2.68 \\
\hline Combination & 2 & 0.67 \\
\hline No breastfeeding & 194 & 64.88 \\
\hline Undefined or not applicable & 15 & \\
\hline When did breastfeeding start?: & 9 & 3.02 \\
\hline Immediately or within one hour of delivery & 7 & 2.34 \\
\hline When kangaroo mother care started & 5 & 1.67 \\
\hline Once reached satisfactory degree of physical maturity & 2 & 0.67 \\
\hline One day or more after birth & 261 & 87.29 \\
\hline After one hour but within 24 h of birth & & \\
\hline Undefined or not applicable & 13 & 4.35 \\
\hline Breastfeeding frequency: & 4 & 1.34 \\
\hline Every two to three hours & 282 & 94.31 \\
\hline Whenever possible & &
\end{tabular}

Table 6. Description of discharge and follow-up characteristics N $=299 \quad \%$

\begin{tabular}{|c|c|c|}
\hline \multicolumn{3}{|l|}{ Discharge criteria: } \\
\hline Clinically stable & 19 & 6.35 \\
\hline Adequate weight gain & 10 & 3.34 \\
\hline Exclusively breastfeeding and consistently gaining weight & 7 & 2.34 \\
\hline Absolute weight cutoff & 5 & 1.67 \\
\hline Neonatologist approval & 1 & 0.33 \\
\hline Within time of birth & 0 & 0.00 \\
\hline Undefined or not applicable & 257 & 85.95 \\
\hline \multicolumn{3}{|l|}{ Discharge timing: } \\
\hline After seven days of life & 8 & 2.68 \\
\hline Within seven days of life & 6 & 2.01 \\
\hline Undefined or not applicable & 285 & 95.32 \\
\hline \multicolumn{3}{|l|}{ Follow-up location: } \\
\hline Facility & 29 & 9.70 \\
\hline Home & 22 & 7.36 \\
\hline Facility and home & 9 & 3.01 \\
\hline Phone call or letter & 1 & 0.33 \\
\hline Undefined or not applicable & 238 & 79.60 \\
\hline \multicolumn{3}{|l|}{ Follow-up time: } \\
\hline$>3$ months to 6 months & 11 & 3.68 \\
\hline$>6$ months to 12 months & 11 & 3.68 \\
\hline Dependent on adequate weight gain & 10 & 3.34 \\
\hline$\leq 1$ months & 8 & 2.68 \\
\hline$>1$ months to 3 months & 8 & 2.68 \\
\hline Until 40 weeks gestational age & 4 & 1.34 \\
\hline$>12$ months to 18 months & 2 & 0.67 \\
\hline Undefined or not applicable & 245 & 81.49 \\
\hline \multicolumn{3}{|l|}{ Compliance with follow-up: } \\
\hline 70 to $<90 \%$ & 11 & 3.68 \\
\hline 90 to $<100 \%$ & 9 & 3.01 \\
\hline$<70 \%$ & 7 & 2.34 \\
\hline $100 \%$ & 2 & 0.67 \\
\hline Undefined or not applicable & 270 & 90.30 \\
\hline
\end{tabular}




\section{Other components}

Studies also described clothing recommendations, newborn positioning, and temperature monitoring during KMC. In 64 studies (21\%) participants were instructed to clothe their infant in only a diaper during kangaroo care, an additional 64 studies (21\%) encouraged use of a diaper, cap, and socks, and 17 (6\%) promoted having the infant naked during SSC contact (Table 7). The majority of studies $(n=179$, $60 \%$ ) instructed participants to position the infant prone on the care provider's chest during SSC, while five studies (2\%) encouraged a side-lying or breastfeeding position. In 59 studies (20\%), the kangaroo care provider was instructed to be in a reclined position, while an upright position was encouraged in 48 studies (16\%). Temperature of the infant was monitored during SSC in 71 studies (24\%).

\section{DISCUSSION}

There is significant heterogeneity in the definition of KMC and a large number of studies did not report a definition of KMC. Of the studies that defined KMC, SSC was present in all studies. Additional KMC components-breastfeeding, early discharge, and follow-up-were missing in the majority of studies. These findings suggest that SSC is accepted in research and programmatic settings as an essential component of KMC, but the other components vary by context, defined as demographic, economic, social, and cultural factors, and newborn characteristics.

The lack of a clear KMC definition and guidance for implementing KMC is a reflection of incomplete evidence. Evidence for KMC is largely based on meta-analyses that combine studies with heterogeneous definitions of KMC and

Table 7. Description of clothing and positioning during kangaroo mother care

\begin{tabular}{|c|c|c|c|c|}
\hline & \multicolumn{2}{|c|}{\begin{tabular}{|l} 
Promoted \\
CLOTHING AND \\
POSHIIONING
\end{tabular}} & \multicolumn{2}{|c|}{$\begin{array}{l}\text { OBgerved } \\
\text { CLOTHING AND } \\
\text { POSIIIONING }\end{array}$} \\
\hline & $\mathrm{N}$ & $\%$ & $\mathrm{~N}$ & $\%$ \\
\hline \multicolumn{5}{|l|}{ Clothing of kangarooed baby: } \\
\hline Diaper or nappy & 64 & 21.40 & 8 & 2.68 \\
\hline Diaper, cap, and socks & 64 & 21.40 & 6 & 2.01 \\
\hline Naked & 17 & 5.69 & 2 & 0.67 \\
\hline Undefined or not applicable & 154 & 51.51 & 283 & 94.65 \\
\hline \multicolumn{5}{|l|}{ Position of kangarooed baby: } \\
\hline Prone on mother's chest & 179 & 59.87 & 17 & 5.69 \\
\hline On side or next to mother & 3 & 1.00 & 1 & 0.33 \\
\hline Breastfeeding position & 2 & 0.67 & 0 & 0.00 \\
\hline Undefined or not applicable & 115 & 38.46 & 281 & 93.98 \\
\hline \multicolumn{5}{|l|}{ Position of provider: } \\
\hline Inclined or reclined & 59 & 19.73 & 8 & 2.68 \\
\hline Upright & 48 & 16.05 & 5 & 1.67 \\
\hline Variation of inclined and upright & 12 & 4.01 & 2 & 0.67 \\
\hline Undefined or not applicable & 180 & 60.20 & 284 & 94.98 \\
\hline
\end{tabular}

occur in different settings [5,6]. Attempts to stratify the association of KMC on outcomes by KMC components, newborn characteristics (birth weight, gestational age), and high NMR vs low NMR often do not yield statistically significant results because of the limited data available. We do not know the effect of different combinations of KMC components, nor do we understand the feasibility with which each component can be implemented effectively in different contexts. Our study was limited by the lack of data on the duration of SSC. Furthermore, measurement of SSC duration was based on mothers' report of time with minimal observational data. Studies where SSC duration was measured by an independent observer may be biased by the Hawthorn effect.

To define the optimal duration of SSC, we need additional data on the dose response of SSC duration on mortality and morbidity outcomes. The benefits of SSC are likely dependent on the duration of SSC, however the duration of SSC must also be balanced with the feasibility of practicing SSC for extended periods of time. In most settings promoting SSC 24 hours a day is not feasible. Understanding the minimal duration of SSC that provides the maximal benefits will provide more specific recommendations. Most studies initiated KMC after stabilization of the newborn and the effect of KMC on mortality and morbidity is generalizable to the population of newborns who survive to be stabilized. The effect of KMC immediately after birth before stabilization is unclear due to inconclusive evidence [14-17]. Additional efforts to test the effect of KMC prior to stabilization and to define stability is needed through further studies or by consulting experts at each level of care (primary, secondary, or tertiary care) through a Delphi method.

To operationalize KMC, the simpler the intervention the more likely it is to scale [18]. A simple and clear operational definition for KMC is needed. Evidence suggests benefits for newborns less than $2000 \mathrm{~g}$, who are stabilized in facilities with SSC as the primary component. More work is needed to improve the measurement of gestational age and improving the recording of birth weights in facilities to better understand the impact of $\mathrm{KMC}$ and for whom there are benefits. Our review suggests that skin-to-skin contact is the core minimal component of KMC and variations depend on context and individual clinical needs of the newborn. For example, extremely preterm newborns who are unable to coordinate their suck and swallow will need feeding support such as nasogastric feeding or intravenous fluid. In high resource settings with space and infection precautions, a provider may recommend SSC for a preterm infant but choose not to discharge early from the facility. To operationalize KMC, a simple matrix that lists newborn characteristics in columns and KMC components in rows for different settings, ie, tertiary, secondary, primary or community levels, can take into account the core SSC com- 
ponents with variations based on differences in the newborn and context.

As implementation of KMC begins to accelerate globally, data on the context, individual newborn factors, and KMC components can be collected and harmonized to generate a model that will best define KMC for a set of individual newborn characteristics in specific settings. Research and programmatic agendas to advance KMC should include a standardized set of indicators and measurement tools that document SSC initiation criteria, SSC duration as number of hours per day promoted and ideally observed, feeding protocols, discharge criteria from a facility to community and follow-up standards, and discharge criteria from KMC. To track progress, indicators and standard measurement tools are needed to measure coverage of key newborn interventions including KMC [19]. The release of the new preterm guidelines by the World Health Organization, where KMC is recommended for all newborns less than $2000 \mathrm{~g}$, will provide an opportunity for programs and researchers to start addressing definition gaps, establish global recommendations of operational definitions and core components of KMC, and accelerate KMC within care of preterm babies.

\section{CONCLUSION}

Developing a standardized operational definition of KMC and employing indicators and measurement tools to measure and evaluate KMC acceleration efforts is needed. More than half of the studies equate KMC with SSC. Moving forward, careful distinction between KMC and SSC is needed. While SSC is beneficial for all newborns, KMC should be clearly defined, at the bare minimum, as a package of interventions including SSC, exclusive breastfeeding, and close monitoring for preterm and/or low birthweight babies. Researchers and program implementers can contribute to building a more solid evidence base for KMC by measuring and reporting how KMC is defined-the components implemented and the feasibility of implementation based on the context-and the outcomes measured. A central and accessible database to share knowledge should contain this data in addition to standardized indicators, such as the proportion of eligible newborns who receive $\mathrm{KMC}$ and the barriers and facilitators to implementation of KMC.

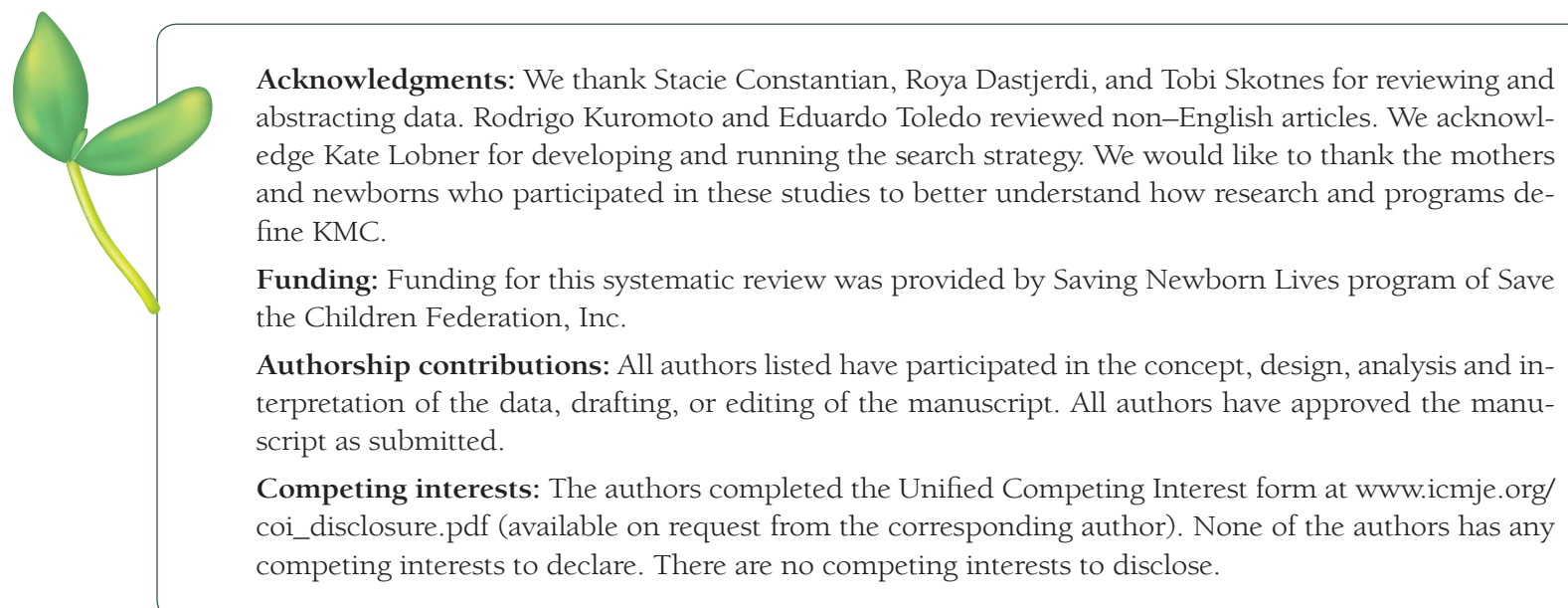

1 Bhutta ZA, Das JK, Bahl R, Lawn JE, Salam RA, Paul VK, et al. Can available interventions end preventable deaths in mothers, newborn babies, and stillbirths, and at what cost? Lancet. 2014;384:347-70. Medline:24853604 doi:10.1016/S0140-6736(14)60792-3

2 Liu L, Oza S, Hogan D, Perin J, Rudan I, Lawn JE, et al. Global, regional, and national causes of child mortality in 2000-13, with projections to inform post-2015 priorities: an updated systematic analysis. Lancet. 2015;385:43040. Medline:25280870 doi:10.1016/S0140-6736(14)61698-6

3 Birthweight L. Country, Regional, and Global Estimate. New York: UNICEF, 2004.

4 Institute of Medicine Committee on Understanding Premature B. Assuring Healthy O. The National Academies Collection: Reports funded by National Institutes of Health. In: Behrman RE, Butler AS, editors. Preterm Birth: Causes, Consequences, and Prevention. Washington (DC): National Academies Press (US). National Academy of Sciences, 2007.

5 Lawn JE, Mwansa-Kambafwile J, Barros FC, Horta BL, Cousens S. Kangaroo mother care to prevent neonatal deaths due to preterm birth complications. Int J Epidemiol. 2010;39:i144-54. Medline:20348117 doi:10.1093/ ije/dyq031 
6 Conde-Agudelo A, Diaz-Rossello JL. Kangaroo mother care to reduce morbidity and mortality in low birthweight infants. Cochrane Database Syst Rev. 2014;4:CD002771. Medline:24752403

7 Dickson KE, Simen-Kapeu A, Kinney MV, Huicho L, Vesel L, Lackritz E, et al. Every Newborn: health-systems bottlenecks and strategies to accelerate scale-up in countries. Lancet. 2014;384:438-54. Medline:24853600 doi:10.1016/S0140-6736(14)60582-1

8 Bahl R, Martines J, Bhandari N, Biloglav Z, Edmond K, Iyengar S, et al. Setting research priorities to reduce global mortality from preterm birth and low birth weight by 2015. J Glob Health. 2012;2:010403. Medline:23198132 doi:10.7189/jogh.01.010403

9 Rudan I, Kapiriri L, Tomlinson M, Balliet M, Cohen B, Chopra M. Evidence-based priority setting for health care and research: tools to support policy in maternal, neonatal, and child health in Africa. PLoS Med. 2010;7:e1000308. Medline:20644640 doi:10.1371/journal.pmed.1000308

10 Engmann C, Wall S, Darmstadt G, Valsangkar B, Claeson M. Consensus on kangaroo mother care acceleration. Lancet. 2013;382:e26-7. Medline:24246562 doi:10.1016/S0140-6736(13)62293-X

11 Bergh AM, Kerber K, Abwao S, de-Graft Johnson J, Aliganyira P, Davy K, et al. Implementing facility-based kangaroo mother care services: lessons from a multi-country study in Africa. BMC Health Serv Res. 2014;14:293. Medline:25001366 doi:10.1186/1472-6963-14-293

12 World Health Organization DoRHaR. Kangaroo mother care: a practical guide. WHO Library. Geneva: World Health Organization, 2003.

13 Bank W. Data: Mortality rate, neonatal (per 1000 live births) 2014. Available: http://data.worldbank.org/indicator/SH.DYN.NMRT. Accessed: 1 October 2014.

14 Ahmed S, Mitra SN, Chowdhury AM, Camacho LL, Winikoff B, Sloan NL. Community Kangaroo Mother Care: implementation and potential for neonatal survival and health in very low-income settings. J Perinatol. 2011;31:361-7. Medline:21311502 doi:10.1038/jp.2010.131

15 Worku B, Kassie A. Kangaroo mother care: a randomized controlled trial on effectiveness of early kangaroo mother care for the low birthweight infants in Addis Ababa, Ethiopia. J Trop Pediatr. 2005;51:93-7. Medline:15840760 doi:10.1093/tropej/fmh085

16 Cattaneo A, Davanzo R, Worku B, Surjono A, Echeverria M, Bedri A, et al. Kangaroo mother care for low birthweight infants: a randomized controlled trial in different settings. Acta Paediatr. 1998;87:976-85. Medline:9764894 doi:10.1111/j.1651-2227.1998.tb01769.x

17 Lincetto O, Nazir AI, Cattaneo A. Kangaroo mother care with limited resources. J Trop Pediatr. 2000;46:293-5. Medline:11077939 doi:10.1093/tropej/46.5.293

18 Atun R, de Jongh T, Secci F, Ohiri K, Adeyi O. Integration of targeted health interventions into health systems: a conceptual framework for analysis. Health Policy Plan. 2010;25:104-11. Medline:19917651 doi:10.1093/ heapol/czp055

19 Moran AC, Kerber K, Sitrin D, Guenther T, Morrissey CS, Newby H, et al. Measuring coverage in MNCH: indicators for global tracking of newborn care. PLoS Med. 2013;10:e1001415. Medline:23667335 doi:10.1371/ journal.pmed.1001415 